\title{
Left-sided primary cardiac lymphoma: a case report
}

\author{
Valentina Scheggi ${ }^{i *}$ (D) Carlotta Mazzoni ${ }^{2}$, Tiziano Mariani ${ }^{2}$ and Pier Luigi Stefàno ${ }^{3}$
}

\begin{abstract}
Background: Primary cardiac lymphoma $(P C L)$ is a rare neoplasm, defined as lymphoma with the main bulk localized in the heart; diffuse large B cell lymphoma (DLBCL) is the most common type. It usually involves the pericardium and the right heart and has a poor prognosis with a median survival of less than 1 year.

Case presentation: A 62-year-old female presented to the emergency department for palpitations and recentonset dyspnea. The echocardiogram showed a round-shaped mass $(33 \times 32 \mathrm{~mm})$ in the left atrium, a mild circumferential pericardial effusion, and a hyperechogenic mass at the level of the atrio-ventricular junction. A thoracic CT scan demonstrated the presence of a bulky mediastinal mass, strictly attached to the left heart and infiltrating its posterior wall, the left pulmonary veins, and the inferior lobar bronchus. The patient underwent CTguided biopsy, and the diagnosis of double-expressor DLBCL was made. Given the potential risk of heart rupture during chemotherapy, the first cycle of R-CHOP was performed in an in-hospital setting, with initial benefit. After completing 6 cycles of R-CHOP, imaging studies showed rapid progression of the disease; the patient was started on the salvation protocol R-DHAOX but died of septic shock 10 months later.
\end{abstract}

Conclusions: $\mathrm{PCL}$ is rare and accounts for less than $2 \%$ of primary cardiac tumors; double-expressor DLBCL carries a poor prognosis.

As in most cases, the diagnosis was made after the onset of nonspecific symptoms (dyspnea) but-despite the strong predilection for right heart involvement reported in literature-our patient had a predominant left atrial infiltration.

Keywords: Primary cardiac lymphoma, Left atrium, Diffuse B cell lymphoma

\section{Background}

Cardiac tumors are infrequent and most often secondary to a metastatic process. Primary cardiac tumors are usually benign, the most prevalent of them being cardiac myxoma.

Primary cardiac lymphoma (PCL) is a rare entity accounting for less than $2 \%$ of primary cardiac tumors: it lacks a univocal definition, and the evidence in literature derives almost exclusively from case reports [1-13].

\footnotetext{
* Correspondence: scheggiv@aou-careggi.toscana.it;

valentina.scheggi@gmail.com

'Cardiothoracovascular Department, Division of Cardiovascular and

Perioperative Medicine, Careggi University Hospital, Largo Brambilla 3, 50133

Florence, Italy

Full list of author information is available at the end of the article
}

Secondary cardiac involvement of a disseminated lymphoma is, on the other hand, quite common.

The diagnostic criteria for PCL have progressively broadened over time. The definition of PCL was initially reserved for a mass with exclusive involvement of the heart or pericardium, while at present, it can be made when the primary bulk of the lymphoma is localized in the heart or pericardium even if limited extracardiac lymphoma is present-mostly when the clinical manifestations are related primarily to cardiac dysfunction $[2,3]$.

PCL is typically a subtype of non-Hodgkin B cell lymphoma, most often diffuse large B cell lymphoma. The overexpression of both C-MYC and BCL2 without a chromosomal rearrangement (double expressor DLBCL), which can be seen in about $20 \%$ of DLBCL, carries a 
poor prognosis, which is even worse if there is a concomitant chromosomal rearrangement of the two genes (double hit-double-expressor DLBCL) [4, 5].

PCL is classically a disease that affects the right heart with a strong predilection for the right atrium: only a few cases of lymphomas with the main bulk at the level of the left sections are present in the literature. Pericardial effusion is often present.

Clinical manifestations of PCL are often vague, which accounts for the late diagnosis and poor prognosis of the disease: the most common symptom is dyspnea. Other clinical signs and symptoms depend largely on the localization of the tumor (e.g., superior vena cava syndrome in case of right heart involvement) and its infiltration of the myocardium or coronary arteries that can be responsible, respectively, for the onset of arrhythmias and angina. Almost half of the patients can experience symptoms of heart failure $[6,7]$.

Multimodality imaging is essential to determine the nature of a cardiac mass and can guide towards the diagnosis of PCL. Echocardiography is usually the first imaging step; cardiac CT and MRI offer further tissue characterization and anatomical information. In contrast, nuclear imaging is most useful in therapeutic management and to evaluate the response to chemotherapy.

Multimodality imaging can help in the characterization of a cardiac tumor: echocardiography is the first choice examination to identify the mass and evaluate its hemodynamic impact; CMR allows better soft-tissue characterization, high resolution, and multiplane images acquisition; CT provides morpho-structural information of the mass and coronary arteries imaging and is the method of choice when CMR is contraindicated. Large size $(\geq 5 \mathrm{~cm})$, irregular margins, pericardial effusion, and invasion of the free wall and/or the adjacent structures are features of malignancy. T1- and T2-weighted imaging (T1W, T2W) do not differentiate benign and malignant masses, while First Pass Perfusion (FPP) and LGE are more accurate [8-10]. Still, a definite diagnosis-ruling out other possible cardiac malignancies like angiosarcoma - can be obtained only through a bioptic exam, necessary to guide treatment strategies.

Six cycles of combination chemotherapy with cyclophosphamide, doxorubicin, vincristine, and prednisone (CHOP) treatment combined with six doses of rituximab given every 21 days is the current standard for diffuse large B cell lymphoma. Consolidation by radiotherapy to initial non-bulky sites has no proven benefit in patients treated with rituximab or not. Debulking surgery can be an option when the mass of the tumor is responsible for symptoms like refractory heart failure or superior vena cava syndrome $[12,13]$.
Myocardial infiltration of the lymphomatous mass potentially exposes to the risk of myocardial rupture during chemotherapy; the prevalence of this catastrophic event is unknown, but it is considered a significant threat, as it can occur spontaneously in patients with extensive myocardial involvement. Various case reports in the literature suggest dose reduction of initial chemotherapy using different protocols, with subsequent escalation to standard dosage to minimize this risk [14].

Individualized strategies are necessary and, once again, imaging techniques can guide towards the decision of a dose reduction balancing its benefits in preventing heart rupture with the possible downside of not obtaining an optimal response to treatment.

\section{Case presentation}

A 62-year-old female presented to the emergency department with the main complaint of palpitations and recent-onset dyspnea on exertion. Her medical history was unremarkable except for previous hospital admission for dyspnea about 1 year before the presentation. At that time, she underwent drainage of a left pleural effusion and pleural biopsy with findings suggestive of an acute and chronic inflammatory process. Neoplastic causes were excluded. She did not have established cardiovascular risk factors.

Clinical examination was unremarkable, except for tachycardia.

The ECG at presentation was notable for sinus tachycardia and diffuse low voltages.

An echocardiogram was performed, which showed a round-shaped mass $(23 \times 13 \mathrm{~mm})$ in the left atrium, attached to its lateral wall, a mild circumferential nonhemodynamically significant pericardial effusion, and a hyperechogenic mass at the level of the atrioventricular junction; the ejection fraction was 0.64 (Fig. 1).

Laboratory exams were significant for microcytic anemia (Hb $10.8 \mathrm{~g} / \mathrm{dL}, \mathrm{MCV} 80 \mathrm{fL}$, reference values 12 $16 \mathrm{~g} / \mathrm{dL}$, and 81-94 fL, respectively), elevated CRP (134 $\mathrm{pg} / \mathrm{dL}$, reference value $<9)$, Beta2 microglobulin (3.3 $\mathrm{mg} / \mathrm{l}$, reference values $1.2-2.5 \mathrm{mg} / \mathrm{l})$, and $\mathrm{LDH}(458 \mathrm{U} / \mathrm{L}$, reference values 84-264), and a mild elevation of the troponin I value $(2.06 \mathrm{mcg} / \mathrm{L}$, reference values $0.00-0.09$ $\mathrm{mcg} / \mathrm{L}$ ). Human immunodeficiency virus (HIV), hepatitis $B$ virus (HBV), and hepatitis $\mathrm{C}$ virus ( $\mathrm{HCV}$ ) serology were negative.

A subsequent thoracic CT scan demonstrated the presence of a mass with colliquative aspects developing around the cardiac structures, strictly attached to the left heart and infiltrating its posterior wall, the left pulmonary veins, and the inferior lobar bronchus. Another mass of similar characteristics surrounded the anterosuperior portion of the right heart. Epiaortic and paratracheal colliquative lymphadenopathies 


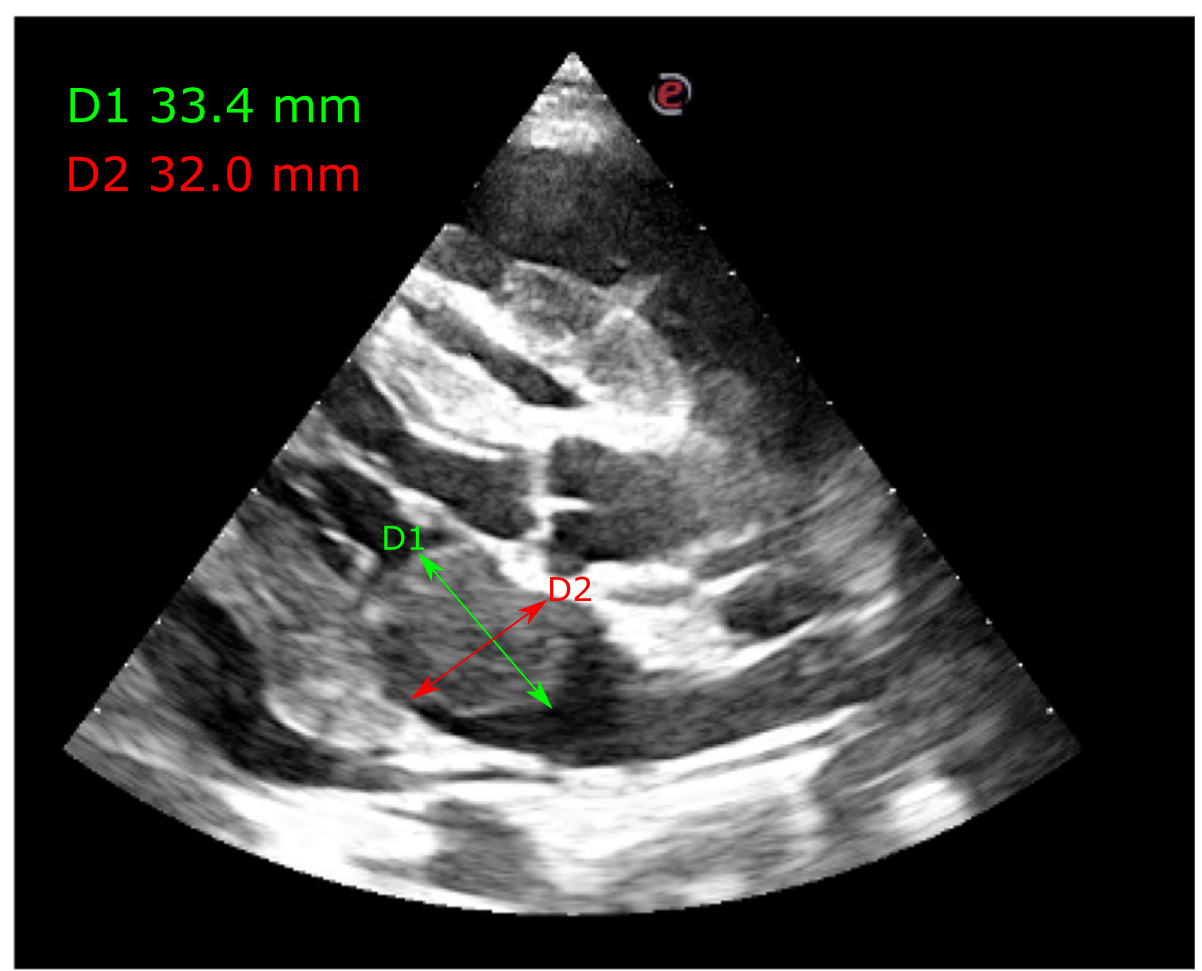

Fig. 1 Transthoracic echocardiography showing the atrial mass, long axis

with a maximum diameter of $2 \mathrm{~cm}$ and a left basal pleural effusion were also present (Fig. 2).

A total-body CT scan excluded the presence of lesions in other districts; cardiac MRI confirmed the malignant nature of the mass (Fig. 3). The patient then underwent a CT-guided biopsy that led to the diagnosis of doubleexpressor diffuse large B cell lymphoma (DLBCL). Immunohistochemistry results were as follows: CD20+, CD3-, CD10-, Bcl6+, Bcl2+, MUM1+, CD23-, CD30-, $\mathrm{Myc}+$; Ki67-index was $80-90 \%$.

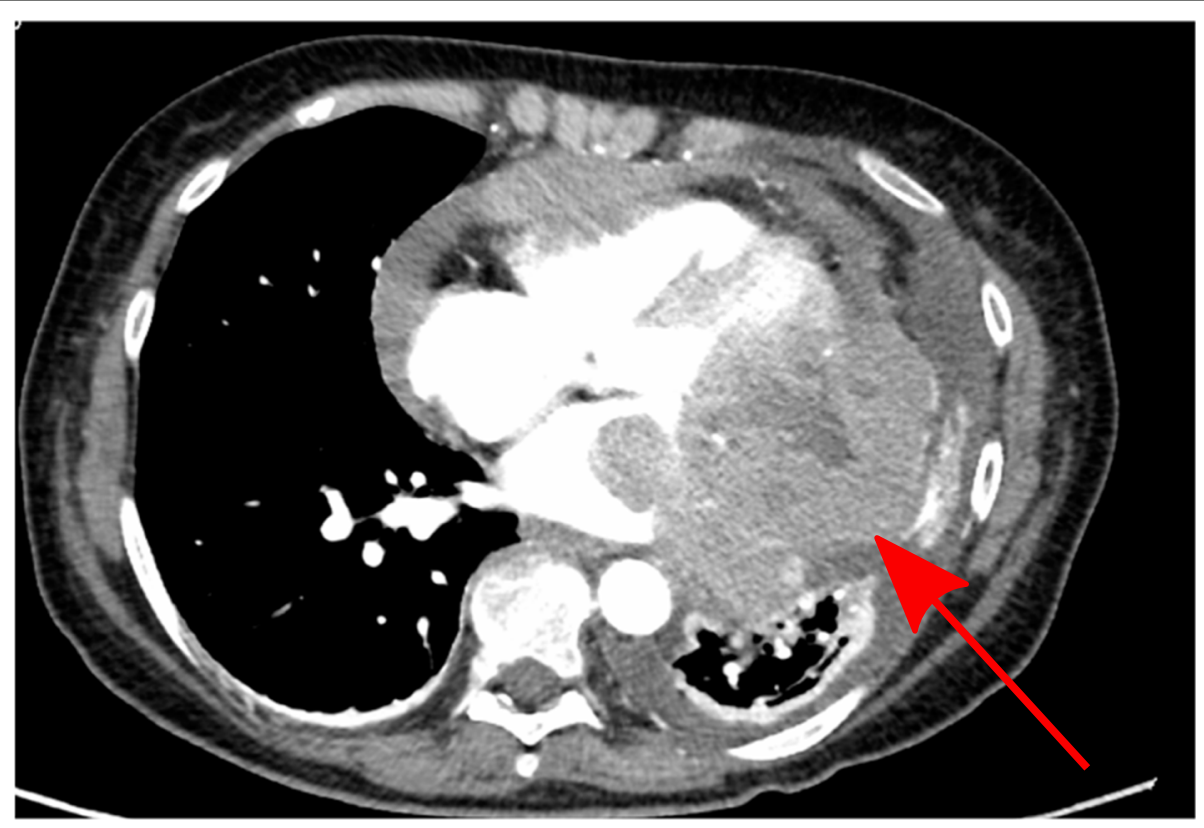

Fig. 2 CT image of the atrial mass and the mediastinal bulky 


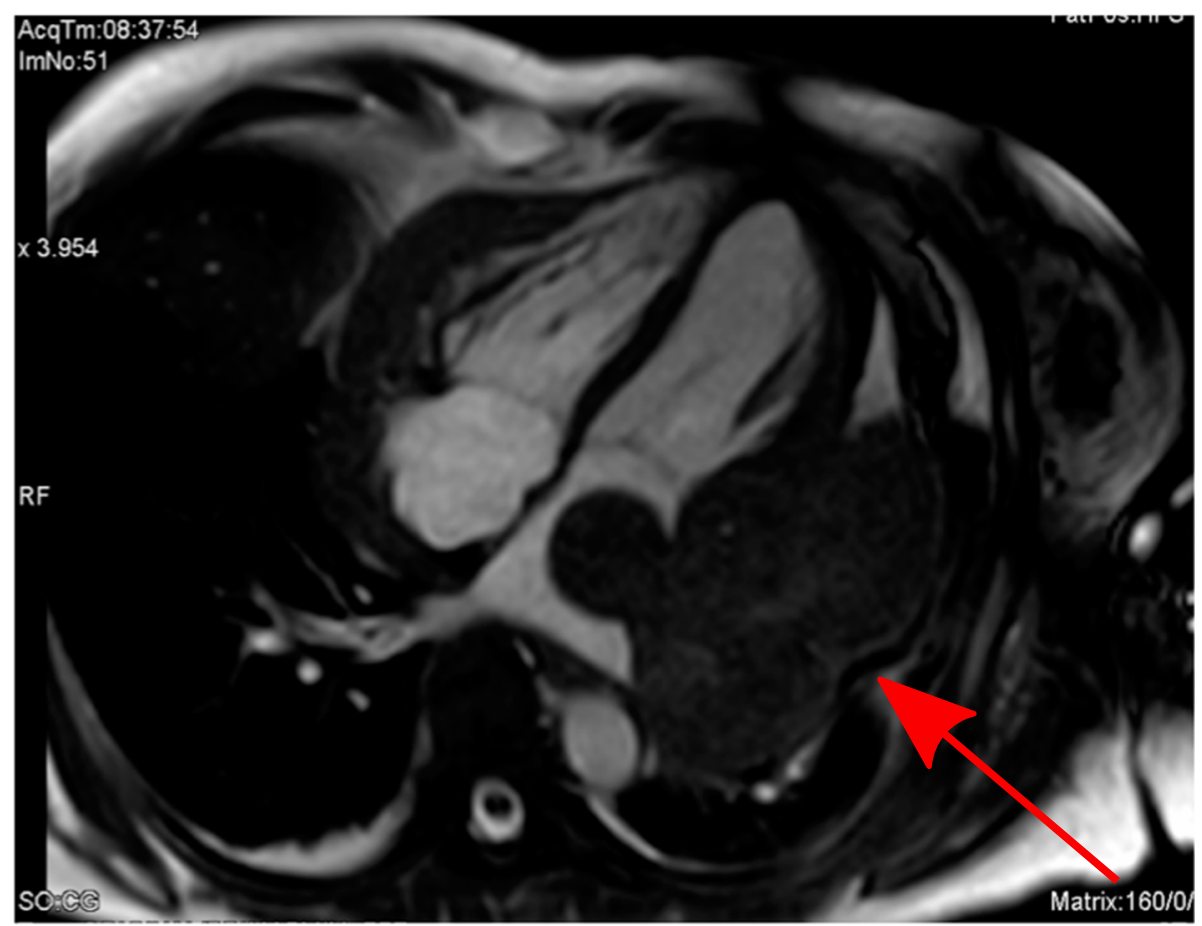

Fig. $3 \mathrm{MRl}$ image of the atrial mass and the mediastinal bulky

The patient did not report B symptoms. IPI was 3. A bone marrow biopsy was negative for the localization of lymphoma.

Due to the significant infiltration of the left atrium and the close attachment of the mass at the level of both left and right ventricular wall, our patient had a potential risk of a heart rupture during chemotherapy; for this reason, the first cycle of R-CHOP21 (rituximab, cyclophosphamide, doxorubicin, vincristine, prednisolone) was performed in a hospital setting with an initial decrease of $75 \%$ of the dosage of doxorubicin. This could guarantee the possibility of a rapid cardiac surgery intervention if needed and was considered the safest option. During the hospital stay, the patient's conditions progressively improved. Sequential echocardiograms documented tumor regression at the level of the left atrium and a repeated CT scan confirmed the reduction of the mass and the lymphadenopathies.

The patient was discharged home and referred to the Hematology Department. During chemotherapy, there was further shrinkage of the tumor documented at PET$\mathrm{CT}$ and regular echocardiographic controls. Still, after the 6th cycle with R-CHOP21, protocol imaging studies showed a rapid progression of the disease.

The patient was immediately started on the salvation protocol R-DHAOX (rituximab dexamethasone cytarabine oxaliplatin) [15] but died of septic shock 10 months after the initial presentation and after the fourth cycle of the second-line chemotherapy.

\section{Conclusions}

PCL is a rare and not well-defined malignancy that accounts for less than $2 \%$ of primary cardiac tumors; double-expressor DLBCL carries a poor prognosis. The overall prognosis is poor, with a median survival of less than 1 year after diagnosis.

Nonspecific signs and symptoms, the rapid evolution of cardiac involvement, and late diagnosis are major factors affecting the outcome.

As in most cases, in our patient, the diagnosis was made after the onset of nonspecific symptoms (dyspnea); despite the strong propensity for right heart involvement reported in the literature, our patient had a rather unusual presentation with a predominant left atrial infiltration.

Individualized strategies are often necessary for treating these patients due to the lack of consistent evidence in the literature and based on the specific characteristics and localization of the tumor.

\section{Abbreviations}

PCL: Primary cardiac lymphoma; DLBCL: Diffuse large B cell lymphoma; $\mathrm{CT}$ : Computed tomography; R-CHOP: Rituximab, cyclophosphamide, hydroxydaunorubicin hydrochloride (doxorubicin hydrochloride), vincristine (Oncovin), and prednisone; R-DHAOX: Rituximab dexamethasone cytarabine oxaliplatin; MRI: Magnetic resonance imaging; ECG: Electrocardiogram; CRP: C-reactive protein

Acknowledgements Not applicable. 


\section{Authors' contributions}

VS made the diagnosis and followed the patient. VS and CM wrote the paper. TM revised the manuscript. PLS was the referral surgeon. The authors read and approved the final manuscript.

\section{Funding}

None to declare.

\section{Availability of data and materials}

Not applicable.

\section{Ethics approval and consent to participate}

Not applicable.

\section{Consent for publication}

At admission, the patient signed a generic informed consent for the treatment of personal data (without a specific indication of the present case report). The patient died, and the relatives of the deceased patient cannot be traced. She was a widow and had only one son who cannot be reached. The case report has been completely anonymized.

\section{Competing interests}

The authors declare that they have no competing interests.

\section{Author details}

${ }^{1}$ Cardiothoracovascular Department, Division of Cardiovascular and Perioperative Medicine, Careggi University Hospital, Largo Brambilla 3, 50133 Florence, Italy. ${ }^{2}$ Division of General Cardiology, Careggi University Hospital, Florence, Italy. 'Division of Cardiac Surgery, Careggi University Hospital, Florence, Italy.

Received: 15 October 2020 Accepted: 8 November 2020

Published online: 19 November 2020

\section{References}

1. Jonavicius K, Salcius K, Meskauskas R, Valeviciene N, Tarutis V, Sirvydis V (2015) Primary cardiac lymphoma: two cases and a review of literature. J Cardiothorac Surg. 10:138

2. Jeudy J, Burke AP, Frazier AA (2016) Cardiac lymphoma. Radiol Clin North Am. 54(4):689-710

3. Chia AXF, Zhao Z, Lim SL (2019) Primary cardiac lymphoma. BMJ Case Rep. 12(12):e230468

4. Yoshihara S, Matsunaga M, Tanioka F, Naito M (2018) Primary cardiac diffuse large B-cell lymphoma. Circ J. 82(11):2919-2920

5. Wan Y, He D, Ye Y, Zhang W, Zhao S, Long Y, Min C, Küçük C (2017) Primary cardiac diffuse large B-cell lymphoma with concurrent high MYC and BCL2 expression in an immunocompetent Chinese elderly woman. Cardiovasc Pathol. 31:54-56

6. Soon G, Ow GW, Chan HL, Ng SB, Wang S (2016) Primary cardiac diffuse large B-cell lymphoma in immunocompetent patients: clinical, histologic, immunophenotypic, and genotypic features of 3 cases. Ann Diagn Pathol. 24:40-46

7. Kumar K, Coulter SA, Baker KR, Cheong BY (2016) Diffuse large B-cell lymphoma presenting as a cardiac mass. Tex Heart Inst J. 43(4):369-371

8. Mousavi N, Cheezum MK, Aghayev A, Padera R, Vita T, Steigner M et al (2019) Assessment of cardiac masses by cardiac magnetic resonance imaging: histological correlation and clinical outcomes. J Am Heart Assoc. 8: e007829

9. Kassop D, Donovan MS, Cheezum MK, Nguyen BT, Gambill NB, Blankstein R et al (2014) Cardiac masses on cardiac CT: a review. Curr Cardiovasc Imaging Rep. 7:9281

10. Pazos-López P, Pozo E, Siqueira ME, García-Lunar I, Cham M, Jacobi A et al (2014) Value of CMR for the differential diagnosis of cardiac masses. JACC Cardiovasc Imaging. 7:896-905

11. Tilly H, Gomes da Silva M, Vitolo U, Jack A, Meignan M, Lopez-Guillermo A, Walewski J, André M, Johnson PW, Pfreundschuh M, Ladetto M (2015) Diffuse large B-cell lymphoma (DLBCL): ESMO Clinical Practice Guidelines for diagnosis, treatment and follow-up. Ann Oncol 26(Suppl 5):v116-v125

12. Ömeroğlu SN, Balkanay OO, Göksedef D, Öz B, İpek G (2018) The surgical treatment of primary cardiac B-cell lymphoma of clinically unstable patient. Ann Thorac Surg. 105(5):e215-e217
13. Tikka J, Vaittinen S, Pakanen L, Lunetta P (2018) sudden unexpected death from unusually large primary cardiac B-cell lymphoma. Am J Forensic Med Pathol. 39(2):161-163

14. Pagé M, Grasso AE, Carpenter JP, Sheppard MN, Karwatowski SP, Mohiaddin $\mathrm{RH}$ (2016) Primary cardiac lymphoma: diagnosis and the impact of chemotherapy on cardiac structure and function. Can J Cardiol 32(7):931. e1-931.e3

15. Manconi L, Coviello E, Canale F, Giannoni L, Minetto P, Guolo F, Clavio M, Marcolin R, Cea M, Cagnetta A, Gobbi M, Miglino M, Ballerini F, Lemoli RM (2020) Dexamethasone, oxaliplatin and cytarabine (R-DHAOx) as salvage and stem cells mobilizing therapy in relapsed/refractory diffuse large B cell lymphomas. Leuk Lymphoma. 61(1):84-90

\section{Publisher's Note}

Springer Nature remains neutral with regard to jurisdictional claims in published maps and institutional affiliations.

\section{Submit your manuscript to a SpringerOpen ${ }^{\circ}$ journal and benefit from:}

- Convenient online submission

- Rigorous peer review

- Open access: articles freely available online

- High visibility within the field

- Retaining the copyright to your article

Submit your next manuscript at $\boldsymbol{\nabla}$ springeropen.com 